\title{
Current situation of minimally invasive glaucoma surgery in Brazil
}

Situação atual de cirurgia minimamente invasiva para glaucoma no Brasil

Marcone Reis Luiz Júnior ${ }^{1}$ (D), Fábio Nishimura Kanadani² (B)

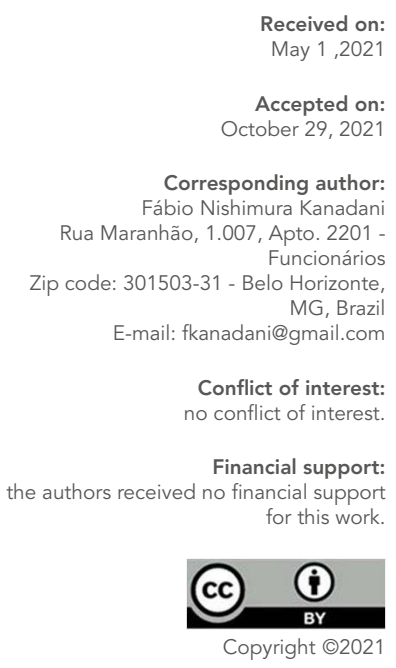

Glaucoma is the leading cause of irreversible blindness in the world, affecting approximately 60 million people; ${ }^{(1)}$ and the estimates for 2040 are over 110 million individuals. ${ }^{(2)}$ The surgical treatment scenario of glaucoma has undergone major changes in recent decades with the introduction of selective laser trabeculoplasty (SLT), less aggressive cyclodestructive procedures and minimally invasive glaucoma surgery (MIGS).

Minimally invasive glaucoma surgery has a better safety profile, providing faster recovery and lower incidence of severe complications, which are often associated with filtering surgeries, such as hypotonia, blebitis and choroidal detachment. ${ }^{(3)}$ On the other hand, it is costly and less effective reducing intraocular pressure (IOP). MIGS is indicated for patients with mild or moderate glaucoma, stable, with indication for cataract surgery phacoemulsification (phaco). ${ }^{(4)}$ In specific cases, it could also be performed alone (stand-alone) in phakic or pseudophakic eyes.

The four main approaches to reducing IOP by MIGS include increasing trabecular outflow through the juxtacanalicular meshwork bypass, increasing uveoscleral outflow through suprachoroidal pathways, reducing aqueous production from the ciliary body, or creating a subconjunctival drainage pathway. ${ }^{(5)}$

Currently, in Brazil, the following types of MIGS are available, acting to increase trabecular outflow: gonioscopy-assisted transluminal trabeculotomy (GATT), ${ }^{(6)}$ Kahook Dual Blade ${ }^{\circledR}(\mathrm{KDB}),{ }^{(7)}$ and the iStent ${ }^{\circledR} \mathrm{G} 1$ and iStent inject ${ }^{\circledR}{ }^{(8)}$ reinforcing the indication in cases of primary open-angle glaucoma (POAG) ${ }^{(9,10)}$ There are descriptions in the literature of GATT in cases of steroid-induced, ${ }^{(11)}$ congenital and juvenile glauco$\mathrm{ma},{ }^{(12)}$ and of KDB in cases of infantile, ${ }^{(13)}$ uveitic $^{(14)}$ glaucoma, and even in appositional angle-closure glaucoma, when the angle opens after the lens extraction. ${ }^{(15)}$

\section{GONIOSCOPY-ASSISTED TRANSLUMINAL TRABECULOTOMY}

Described in 2014, the GATT involves the introduction of a microcatheter circumferentially running through Schlemm's canal, creating a $360^{\circ}$ ab interno trabeculotomy. ${ }^{(6)}$ Alternatively, suture with Prolene ${ }^{\circledR}$ or Nylon 5-0 or 6-0 with a tip modified by cautery can be used, reducing costs, and maintaining safety profile and results. ${ }^{(16)}$

Grover et al. ${ }^{(17)}$ followed up 198 patients undergoing GATT for 24 months, and found a mean IOP reduction by $9.2 \mathrm{mmHg}$ in POAG patients, and a mean reduction of 1.43 medication. The mean reduction was $37.3 \%$, with hyphema as the most common postoperative complication, observed in 23 to $38 \%$ of cases. ${ }^{(6)}$ 


\section{ISTENT® (FIRST GENERATION-G1)}

The iStent ${ }^{\circledR}$ G1 is a snorkel-shaped, heparin-coated titanium non-ferromagnetic device inserted into the trabecular meshwork improving communication with Schlemm's canal.(9)

In a multicenter study involving 240 eyes with cataract and POAG, randomized into two groups to receive phaco alone or phaco-iStent ${ }^{\circledR}$, the latter performed significantly better, with $72 \%$ achieving the desired outcome. An IOP of $<22$ $\mathrm{mmHg}$ without glaucoma medications was observed as compared to $50 \%$ in the control group at one-year follow-up. ${ }^{(18)}$ The most common complications included hyphema, mispositioning, and obstruction by iris, blood, or vitreous, occurring in 3 to $20 \%$ of cases. ${ }^{(9)}$

\section{ISTENT INJECT®}

The iStent inject ${ }^{\circledR}$ consists of two small titanium stents coated with heparin, inserted in the nasal portion of the trabecular meshwork, and placed 2 to 3 clock hours apart.

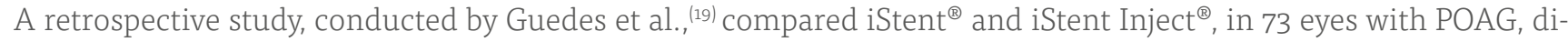
vided into two groups. Six months after surgery, it demonstrated an IOP reduction from 16.5 to $13.9 \mathrm{mmHg}$ in the eyes with iStent ${ }^{\circledR} \mathrm{G}$, and from 17.3 to $12.7 \mathrm{mmHg}$ in those with iStent inject ${ }^{\circledR}$. This reduction was significantly greater in iStent inject ${ }^{\circledR}$ eyes than in iStent ${ }^{\circledR}$ G1 eyes (26.6 versus $15.8 \%$ ).

\section{KAHOOK DUAL BLADE®}

The KDB consists of partial excision of the trabecular meshwork by a modified goniotomy blade, and creation of a straight opening for Schlemm's canal. KDB has a theoretical advantage over other trabeculotomy procedures, such as GATT, since it removes the trabecular meshwork tissue and leaves no residual leaflets that could lead to fibrosis over time. ${ }^{(20)}$

Dorairaj et al. ${ }^{(7)}$ evaluated 52 eyes undergoing phaco-KDB, and reported the mean IOP reduced from 16.8 at baseline to $12.4 \mathrm{mmHg}$ after 12 months, a reduction by $26.2 \%$. Another retrospective study compared phaco-KDB with phaco-GATT, and 6 months later, $81.7 \%$ of KDB eyes and $84.6 \%$ of GATT eyes achieved surgical success (20\% IOP reduction or reduction in use of ocular hypotensive medication). Eighty percent of eyes submitted to KDB achieved target IOP $\leq 18 \mathrm{mmHg}$ versus $59.3 \%$ for GATT, and $61.4 \%$ of eyes submitted to KDB achieved IOP $\leq 15 \mathrm{mmHg}$ versus $25.9 \%$ for GATT. Therefore, the reductions in mean IOP and medications were similar in the groups, but a higher percentage in the KDB group reached the target IOP. ${ }^{(21)}$ Complications included hyphema, transient IOP elevation, corneal edema, iris recess, cyclodialysis, and Descemet's membrane detachment. ${ }^{(7,2)}$

Although the literature lacks more randomized studies with no participation of the health product industries, the results demonstrated over these years justify the indication of MIGS in cases of stable mild or moderate glaucoma, especially in eyes that will undergo cataract surgery.

When comparing these three alternatives, it is important to consider the different surgical techniques, bearing in mind the learning curve, from the easiest to the hardest modality - iStent ${ }^{\circledR}-\mathrm{KDB}-$ GATT; procedure costs - GATT $<$ KDB < iStent ${ }^{\circledR}$; and the power to reduce IOP - Gatt $\geq$ KDB > iStent ${ }^{\circledR}$.

It is important to understand that MIGS is not intended to fully replace more invasive surgeries, such as trabeculectomy or drainage implants. However, it is a valuable option for glaucoma surgeons, for being less invasive, safe, effective in reducing IOP, and capable of improving prognosis of the disease and patient's quality of life.

\section{REFERENCES}

1. Quigley HA, Broman AT. The number of people with glaucoma worldwide in 2010 and 2020. Br J Ophthalmol. 2006 Mar;90(3):262-7.

2. Tham YC, Li X, Wong TY, Quigley HA, Aung T, Cheng CY. Global prevalence of glaucoma and projections of glaucoma burden through 2040: a systematic review and meta-analysis. Ophthalmology. 2014 Nov;121(11):2081-90.

3. Azuara-Blanco A, Katz LJ. Dysfunctional filtering blebs. Surv Ophthalmol. 1998;43(2):93-126.

4. Richter GM, Coleman AL. Minimally invasive glaucoma surgery: current status and future prospects. Clin Ophthalmol. 2016 Jan 28;10:189-206.

5. Gillmann K, Mansouri K. Minimally Invasive Glaucoma Surgery: Where Is the Evidence? Asia Pac J Ophthalmol (Phila). 2020;9(3):203-14.

6. Grover DS, Godfrey DG, Smith O, Feuer WJ, Montes de Oca I, Fellman RL. Gonioscopy-assisted transluminal trabeculotomy, ab interno trabeculotomy: technique report and preliminary results. Ophthalmology. 2014;121(4):855-61.

7. Dorairaj SK, Seibold LK, Radcliffe NM, Aref AA, Jimenez-Román J, Lazcano-Gomez GS, et al. 12-Month Outcomes of Goniotomy Performed Using the Kahook Dual Blade Combined with Cataract Surgery in Eyes with Medically Treated Glaucoma. Adv Ther. 2018;35(9):1460-9.

8. Spiegel D, Wetzel W, Haffner DS, Hill RA. Initial clinical experience with the trabecular micro-bypass stent in patients with glaucoma. Advances in Therapy. $2007 ; 24(1): 161-70$. 
9. Resende AF, Patel NS, Waisbourd M, Katz LJ. iStent ${ }^{\circledR}$ Trabecular Microbypass Stent: An Update. J Ophthalmol. 2016;2016:2731856.

10. Brandão LM, Grieshaber MC. Update on Minimally Invasive Glaucoma Surgery (MIGS) and New Implants. J Ophthalmol. $2013 ; 2013: 705915$.

11. Boese EA, Shah M. Gonioscopy-assisted Transluminal Trabeculotomy (GATT) is An Effective Procedure for Steroid-induced Glaucoma. J Glaucoma. 2019 Sep;28(9):803-7

12. Grover DS, Smith O, Fellman RL, Godfrey DG, Butler MR, Montes de Oca I, et al. Gonioscopy assisted transluminal trabeculotomy: an ab interno circumferential trabeculotomy for the treatment of primary congenital glaucoma and juvenile open angle glaucoma. Br J Ophthalmol. 2015;99(8):1092-6.

13. Khouri AS, Wong SH. Ab interno trabeculectomy with a dual blade: surgical technique for childhood glaucoma. J Glaucoma. $2017 ; 26(8): 749-51$.

14. Miller VJ, Young CEC, SooHoo JR, Seibold LK, Kahook MY, Pecen PE, et al. Efficacy of goniotomy with kahook dual blade in patients with uveitis-associated ocular hypertension. J Glaucoma. 2019;28(8):744-8.

15. Dorairaj S, Tam MD. Kahook dual blade excisional goniotomy and goniosynechialysis combined with phacoemulsification for angle-closure glaucoma: 6-month results. J Glaucoma. 2019;28(7):643-6.

16. Grover DS, Fellman RL. Gonioscopy-assisted transluminal trabeculotomy (gatt): thermal suture modification with a dye-stained rounded tip. J Glaucoma. 2016;25(6):501-4.

17. Grover DS, Smith O, Fellman RL, Godfrey DG, Gupta A, Montes de Oca I, et al. Gonioscopy-assisted Transluminal Trabeculotomy: An Ab Interno Circumferential Trabeculotomy: 24 Months Follow-up. J Glaucoma. 2018;27(5):393-401.

18. Samuelson TW, Katz LJ, Wells JM, Duh YJ, Giamporcaro JE; US iStent Study Group. Randomized evaluation of the trabecular micro-bypass stent with phacoemulsification in patients with glaucoma and cataract. Ophthalmology. 2011;118(3):459-67.

19. Guedes RA, Gravina DM, Lake JC, Guedes VM, Chaoubah A. Intermediate results of iStent or iStent inject implantation combined with cataract surgery in a realworld setting: a longitudinal retrospective study. Ophthalmol Ther. 2019;8(1):87-100.

20. Seibold LK, Soohoo JR, Ammar DA, Kahook MY. Preclinical investigation of ab interno trabeculectomy using a novel dual-blade device. Am J Ophthalmol. 2013;155(3):524-529.e2

21. Hirabayashi MT, Lee D, King JT, Thomsen S, An JA. Comparison of surgical outcomes of $360^{\circ}$ circumferential trabeculotomy versus sectoral excisional goniotomy with the Kahook dual blade at 6 months. Clin Ophthalmol. 2019;13:2017-24.

22. EIMallah MK, Seibold LK, Kahook MY, Williamson BK, Singh IP, Dorairaj SK; KDB Goniotomy Study Group. 12-month retrospective comparison of Kahook dual blade excisional goniotomy with iStent trabecular bypass device implantation in glaucomatous eyes at the time of cataract surgery. Adv Ther. 2019;36(9):2515-27. 